\title{
Relationship of vascular variations with liver remnant volume in living liver transplant donors
}

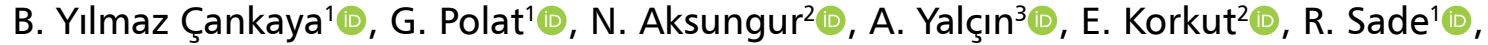

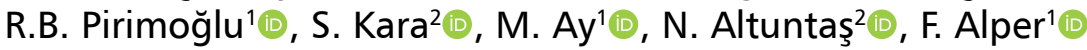 \\ ${ }^{1}$ Department of Radiology, Atatürk University School of Medicine, Erzurum, Turkey \\ ${ }^{2}$ Department of General Surgery, Atatürk University School of Medicine, Erzurum, Turkey \\ ${ }^{3}$ Department of Radiology, Binali Yıldırım University Mengücek Gazi Training and Research Hospital, Erzincan, Turkey
}

[Received: 9 June 2020; Accepted: 19 June 2020; Early publication date: 29 July 2020]

\begin{abstract}
Background: In this study, we investigated the relationship between the portal vein and hepatic artery variations and the remaining liver volume in living donors in liver transplantation.

Materials and methods: In the study, triphasic abdominal computed tomography images of 180 live liver donor candidates were analysed retrospectively. Portal veins were divided into four groups according to the Nakamura classification and seven groups according to the Michels classification. The relationship between vascular variations and remnant liver volume was compared statistically.

Results: According to the Nakamura classification, there were 143 (79.4\%) type A, 23 (12.7\%) type B, 7 (3.9\%) type C and 7 (3.9\%) type D cases. Using the Michels classification, 129 (71\%) type 1, 12 (6.7\%) type 2, 24 (13\%) type 3, 2 (2.2\%) type 4, 10 (5.6\%) type 5, 1 (0.6\%) type 6, and 2 (1.1\%) type 7 cases were detected. There was no significant difference in the percentage of the remaining volume of the left liver lobe between the groups ( $p=0.055, p=0.207$, respectively). Conclusions: Variations in the hepatic artery and portal vein do not affect the remaining liver volume in liver transplantation donors. (Folia Morphol 2021; 80, 3: 590-595)
\end{abstract}

Key words: portal vein, hepatic artery, anatomic variations, liver remnant volume, liver transplantation, living donor

\section{INTRODUCTION}

An accurate evaluation of potential living donors before liver transplantation is important in preventing postoperative liver failure [19]. There are many factors related to donor safety, such as obesity, age, liver volume, fatty liver, medical problems, anatomical variations, surgical process, and operative procedures [20]. The correct assessment of liver vascularity and volume is very important for both the donor and the recipient $[15,19]$. Post-transplantation liver fail- ure has been reported in the right lobe donors at around $10 \%$ [15]. On the other hand, the low liver volume of the recipient is an important problem that affects the recovery rate $[8,15]$. Triphasic abdominal computed tomography (CT) imaging has minimised errors in vascular and volume assessment [15]. The determination of vascular variations is essential for the operative procedure because they can affect decisions regarding the resection line or the use of grafts $[20,22]$ A minimum of $30 \%$ of liver remnant

Address for correspondence: Dr. B. Yılmaz Çankaya, Atatürk University School of Medicine, Department of Radiology, Erzurum, Turkey, e-mail: dr.bycankaya@gmail.com

This article is available in open access under Creative Common Attribution-Non-Commercial-No Derivatives 4.0 International (CC BY-NC-ND 4.0) license, allowing to download articles and share them with others as long as they credit the authors and the publisher, but without permission to change them in any way or use them commercially. 

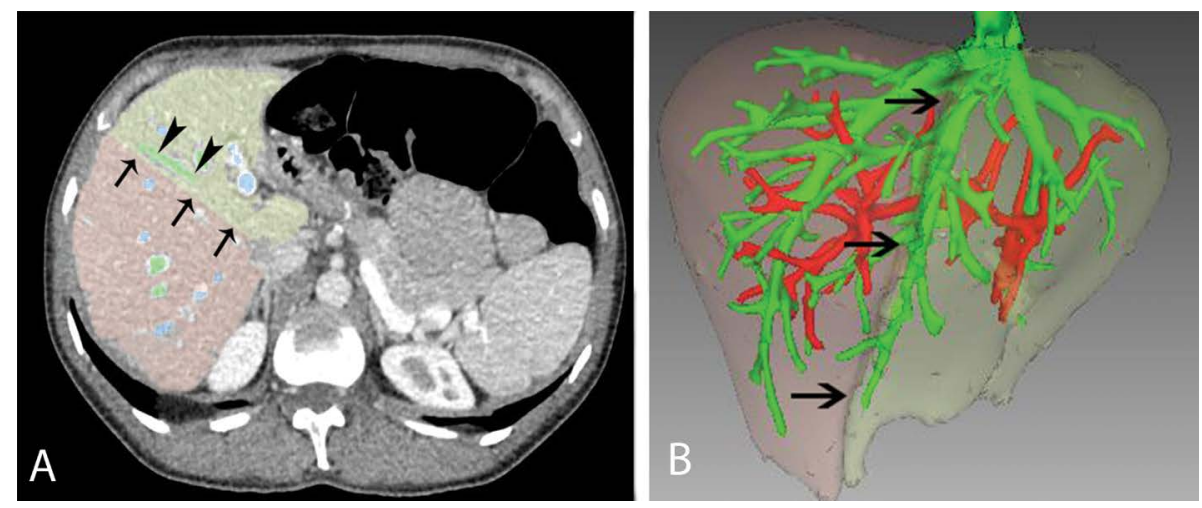

Figure 1. A. The operation resection line (arrows) is made to pass right of the middle hepatic vein (arrowheads); B. Liver volume is calculated by distinguishing it from vascular structures through the three-dimensional volume programme.

volume after post-transplantation is considered as the critical limit $[8,19]$. Therefore, researchers have explored the relationships between liver volume and vascular structures $[3,9,12,18]$. Similarly, in this study, we examined the relationship of the portal and hepatic artery variations, which are surgically important parameters before liver transplantation, with the remnant liver volume in liver transplant donors.

\section{MATERIAL AND METHODS}

\section{Patient selection}

This study was approved by the local ethics committee (number file: B.30.2.ATA.0.01.00/163). All donors were informed about the examination and study procedure, and their written consent was obtained. Of the healthy volunteers who presented to the radiology department of our hospital between July 2018 and January 2020 as potential transplant donors, those aged 18 to 45 years were included in the evaluation. A routine laboratory evaluation, haemogram analysis, liver ultrasonography, and triphasic abdominal CT were performed. After the laboratory and radiological evaluation, 25 patients with fatty liver, 2 with an abdominal aortic aneurysm, and 13 with diffuse atherosclerosis in vascular structures were excluded from the study. The data of the remaining 180 volunteers were evaluated in the study.

\section{CT examination}

In this study, a 320-row multi-detector CT device (Aquillion ONE Vision; Toshiba Medical Systems Corporation, Otawara, Japan) was used for liver imaging. All CT scans were performed using the parameters recommended by the manufacturer (slice thickness: $0.5 \mathrm{~mm}$; rotation time: $0.5 \mathrm{~s}$; and scan interval:
$240 \mathrm{~mm}$ [480 slices, $0.5 \mathrm{~mm}$ ]). Using a pressure injector, $1.5 \mathrm{~mL} / \mathrm{kg}$ contrast enhancement $(300 \mathrm{mg} / \mathrm{mL}$ iohexol) was applied at a rate of $3.5 \mathrm{~mL} / \mathrm{s}$. Triphasic images were obtained in the arterial, portal, and hepatic vein phases. The images were evaluated on the radiological workstation (Syngo Via Console, software version 2.1, Siemens AG Medical Solutions, Erlangen, Germany) by a single radiologist (B.Y.C.) with 10 years' experience in the field. The volumetric volume assessment of the liver was undertaken using another workstation (Myrian Pro; Intrasense, Montpellier, France).

\section{Image evaluation}

The images were divided into groups according to Nakamura et al.'s [16] anatomic classification of portal veins and Michels et al.'s [5] classification of hepatic arteries. In a three-dimensional (3D) volumetric image processor, the liver parenchymal volume was distinguished from vascular structures (Fig. 1A). Along the Cantlie line used during transplantation (Fig. 1B), the liver was volumetrically divided into two lobes as right and left. The percentage of the remnant left lobe relative to the total liver volume was determined after liver transplantation.

\section{Statistical evaluation}

Statistical evaluation was performed using Medcalc statistics (v. 12, Mariagerke, Belgium). The D'Agostino-Pearson test was used to determine whether the data was parametric. The left liver lobe percentages of the four groups formed according to the portal vein classification were compared using the Kruskal-Wallis test. The left liver lobe percentages of the five arterial variation groups formed according to the hepatic artery classification were compared by the 

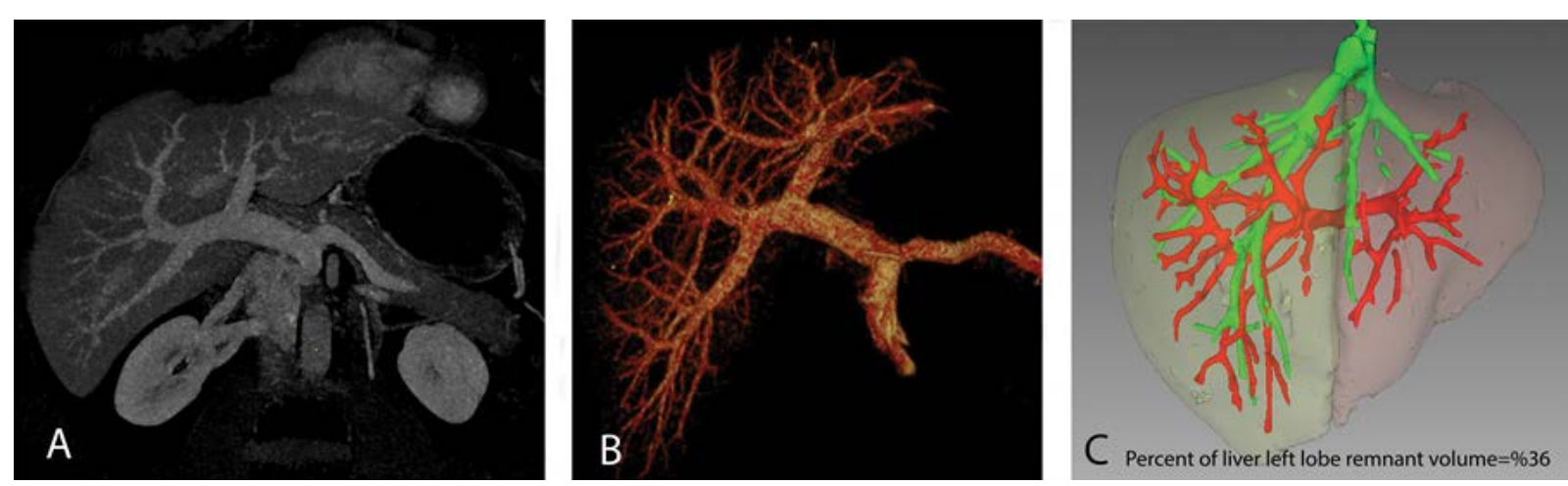

Figure 2. Computed tomography (A) and three-dimensional (3D) volume rendering imaging (B) show the Nakamura type A portal bifurcation structure. The 3D volumetric programme (C) demonstrated liver left lobe volume values in the donor with Nakamura type A.

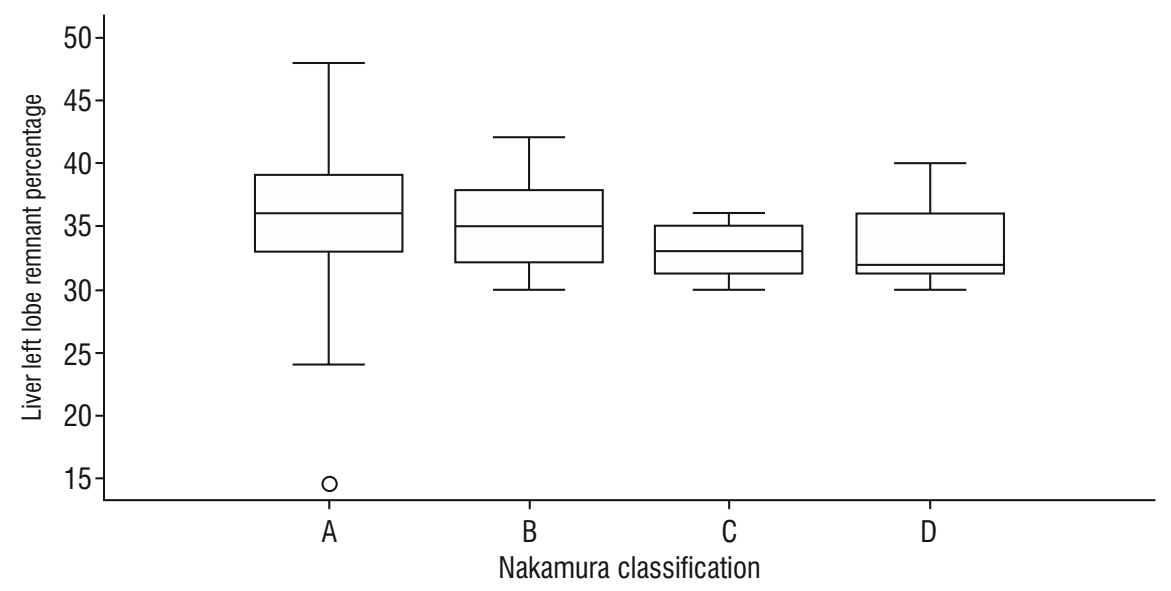

Figure 3. Statistical graph of percentages of left lobe percentage volume according to Nakamura classification.

Kruskal-Wallis test. The demographic data between the groups were comparatively evaluated using the t-test for age and the $\chi^{2}$ test for gender. $P$ values of $<0.05$ were considered as statistically significant.

\section{RESULTS}

The mean age of the 180 volunteers evaluated was $28 \pm 8.5$ years. The number of female volunteers was 76 (41.1\%). According to the Nakamura classification, there were 143 (79.4\%) type $A$, $23(12.7 \%)$ type B, 7 (3.9\%) type C, and 7 (3.9\%) type $D$ patients. There was no statistically significant difference in age and gender distribution between the groups ( $p=0.54$ and 0.096 , respectively). The data of the left liver lobe volume were non-parametric and did not show normal distribution. In the portal vein groups (types A, B, C, and D), the median values $(95 \%$ confidence interval $[\mathrm{Cl}])$ of the left liver lobe volume were found to be 36 (35-37), 35 (33-37), 33 (30.5-35.5), and 32 (30.5-38.5), respectively. There was no significant difference between the Nakamura groups in terms of the left lobe remnant percentage relative to the liver transplantation resection line ( $p=0.055$; Figs. 2,3 ). The related data and statistical results are shown in Table 1.

According to the Michels classification, the following seven groups were observed: type 1 ( $n=129$; $71 \%)$, type 2 ( $n=12 ; 6.7 \%)$, type $3(n=24 ; 13 \%)$, type $4(n=2 ; 2.2 \%)$, type $5(n=10 ; 5.6 \%)$, type 6 ( $n=1 ; 0.6 \%)$, and type $9(n=2 ; 1.1 \%)$. There was no statistical difference in age and gender distribution between these groups ( $p=0.341$ and 0.132 , respectively). In the hepatic artery groups (types 1,2 , $3,4,5,6$, and 9), the median values of the left liver lobe volume $(95 \% \mathrm{Cl})$ were found to be 36 (35-37), 34.5 (30.3-38.8), 35 (32-37), 39, 36.5 (33-42), 42, and 30 . No significant difference was determined between the Michels groups in relation to the percentage of the left lobe remnant volume relative to the liver transplantation resection line $(p=0.207$; Figs. 4, 5). Table 2 presents the related data and statistical results. 
Table 1. Nakamura groups, the left lobe remnant percentage relative to the liver transplantation resection line (source: [16])

\begin{tabular}{|c|c|c|c|c|c|}
\hline Portal vein statistics data & Nakamura type A & Nakamura type B & Nakamura type C & Nakamura type D & $\mathbf{P}$ \\
\hline Number of cases & 143 & 23 & 7 & 7 & \\
\hline Age [year] & $30.4 \pm 8.4$ & $30.4 \pm 8.7$ & $31.2 \pm 10.4$ & $26.1 \pm 6.8$ & 0.54 \\
\hline Male gender (\%) & $85(59 \%)$ & $9(39 \%)$ & $5(71 \%)$ & $5(71 \%)$ & 0.096 \\
\hline $\begin{array}{l}\text { Left lobe volume percentage, } \\
\text { median ( } 95 \% \mathrm{Cl})\end{array}$ & $36(35-37)$ & $35(33-37)$ & $33(30.5-35.5)$ & $32(30.5-38.5)$ & 0.055 \\
\hline
\end{tabular}

$\mathrm{Cl}$ - confidence interval

Table 2. Michels groups, the left lobe remnant percentage relative to the liver transplantation resection line (source: [16])

\begin{tabular}{lcccccccc}
\hline $\begin{array}{l}\text { Hepatic artery } \\
\text { statistics data }\end{array}$ & $\begin{array}{c}\text { Michels } \\
\text { type 1 }\end{array}$ & $\begin{array}{c}\text { Michels } \\
\text { type 2 }\end{array}$ & $\begin{array}{c}\text { Michels } \\
\text { type 3 }\end{array}$ & $\begin{array}{c}\text { Michels } \\
\text { type 4 }\end{array}$ & $\begin{array}{c}\text { Michels } \\
\text { type 5 }\end{array}$ & $\begin{array}{c}\text { Michels } \\
\text { type 6 }\end{array}$ & $\begin{array}{c}\text { Michels } \\
\text { type 9 }\end{array}$ & $\begin{array}{c}\text { P } \\
\text { Number of cases }\end{array}$ \\
\hline $129(71 \%)$ & $12(6.7 \%)$ & $24(13 \%)$ & $2(2.2 \%)$ & $10(5.6 \%)$ & $1(0.6 \%)$ & $2(1.1 \%)$ & \\
Age & $30.8 \pm 8.4$ & $23.5 \pm 5.7$ & $30.5 \pm 8.8$ & $21 \pm 2.8$ & $30.9 \pm 9.6$ & $26 \pm 0$ & $24 \pm 2.8$ & 0.341 \\
Male gender (\%) & $76(58.9 \%)$ & $5(41.7 \%)$ & $13(13.3 \%)$ & $2(100 \%)$ & $6(60 \%)$ & $1(100 \%)$ & $1(50 \%)$ & 0.132 \\
$\begin{array}{l}\text { Left lobe volume percentage, } \\
\text { median (95\% Cl) }\end{array}$ & $36(35-37)$ & $34.5(30.3-38.8)$ & $35(32-37)$ & $39(-)$ & $36.5(33-42)$ & $42(-)$ & $30(-)$ & 0.207 \\
\hline
\end{tabular}

$\mathrm{Cl}$ - confidence interval
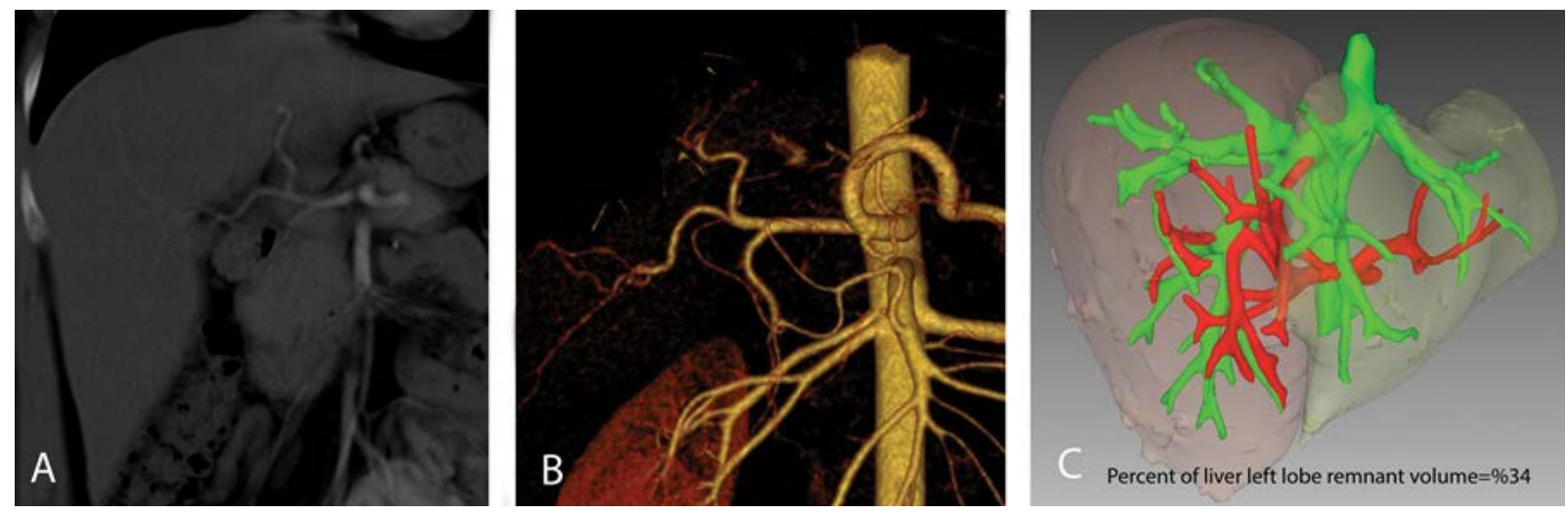

Figure 4. Computed tomography (A) and three-dimensional (3D) volume rendering imaging (B) show the Michel's type 1 hepatic artery variation. The 3D volumetric programme (C) demonstrated liver left lobe volume values in the donor with Michel's type 1 hepatic artery variation.

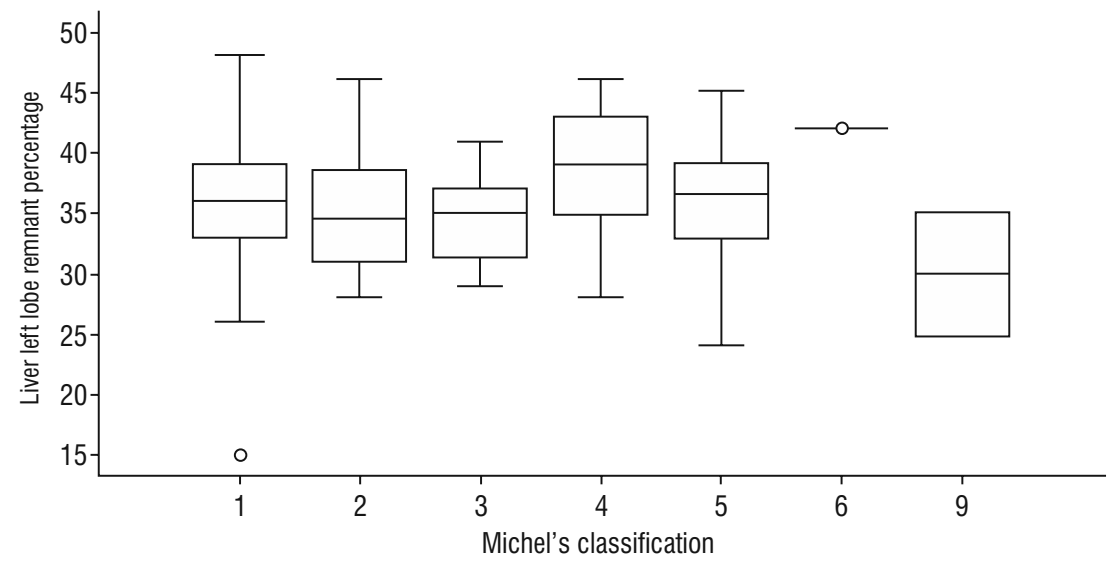

Figure 5. Statistical graph of percentages of left lobe percentage volume according to Michel's classification. 


\section{DISCUSSION}

In this study, we found that the volume of the left liver lobe was not affected by the portal vein and hepatic artery variations which are important pre-transplantation parameters that determine donor safety and success of the procedure. In the literature, there are some studies that has investigated the effects and relationship of vascular structures concerning liver volume $[3,12,18]$. Since 3D software providing preoperative volumetric evaluation is not available in every centre, researchers have attempted to perform this evaluation using various formulas [14]. In this study, we examined the relationship of the liver remnant volume with the portal vein and hepatic artery anatomical variations, which, to the best of our knowledge, has not been previously evaluated in the literature.

Some external anatomic landmarks can be used to divide the liver into the lobes; however, this approach is not sufficient when planning a liver surgery. Further division of the liver into the segments based on the biliary and vascular trees was introduced previously [4, 7]. On the other hand, various anatomical variations of the liver were reported [17] which can affect the volumetric evaluation. The development of the portal and hepatic venous system is completed at the end of $6^{\text {th }}$ week of development. Embryological origin of the liver veins can conflict with Couinaud's model and segmental anatomy is closely related with an adaptive mechanism of the liver which varies with metabolic demand and perfusion [7].

Abdalla et al. [1] performed the volumetric evaluation of the left lobe and left lobe segmentation and found differences between the patients with a certain standard deviation. It was reported that these differences might be due to anatomical differences [1]. Therefore, they may result from either physical differences or vascular variations between patients. In another study, Altunkaynak et al. [2] showed that the body mass index of the patients was associated with their liver volume. Kokuda et al. [13] detected differences between study groups in terms of liver volume and attributed it to the thoracic width. Such studies demonstrate that liver volume can vary according to the populations examined and their anatomical differences. The current study was conducted in a Turkish population, and no significant difference was observed between the groups in terms of age and gender. Therefore, we focused on the effects of vascular variations on the liver volume in our study.

Vascular variations are important anatomical markers that determine liver segmentation [10]. In particular, portal and hepatic variations are vascular components used in liver segmentation. Therefore, variational changes can affect segmentation (including the right-left lobe separation) [10]. Besides, the proper functioning of the portal vein, hepatic artery, and hepatic vein structures that provide tissue vascularisation allows for the volumetric and functional development of the related tissues $[6,11,21]$. Due to the changes in liver function caused by these functional variations in vascular structures, the differences in anatomical structures and their features may also affect the liver. Similarly, Choi et al. [3] reported that the portal vein flow was related to the volume ratios of the right and left liver lobes; thus, they concluded that vascular drainage might affect the liver volume and functional capacity. However, in the same study, it was shown that the portal vein area was not associated with liver volume [3]. Although no variational assessment was undertaken in this study, the portal vein area was not associated with liver volume which was an important finding revealing that the differences in anatomical structures did not affect the volume. Our results confirmed that the anatomical variations did not result in any changes in the liver volume percentage.

\section{Limitations of the study}

Our study had several limitations. First, the number of our patients was not sufficient. Thus, some vascular variations might not be observed, and some were few in statistical terms. The second limitation of our study was that we did not take our patients' body mass indices into account. However, we believe that this parameter would not have had a significant impact on the results as there was no difference in age or gender distribution in the study population.

\section{CONCLUSIONS}

In conclusion, variational changes in the hepatic artery and portal vein are important markers that affect decisions concerning the surgical procedure; however, they do not affect the remnant liver volume in liver transplant donors.

\section{Conflict of interest: None declared}

\section{REFERENCES}

1. Abdalla EK, Denys A, Chevalier P, et al. Total and segmental liver volume variations: implications for liver surgery. Surgery. 2004; 135(4): 404-410, doi: 10.1016/j. surg.2003.08.024, indexed in Pubmed: 15041964. 
2. Altunkaynak BZ, Altunkaynak ME. Relationship of body weight and volume of liver. A morphometrical and stereological study. Saudi Med J. 2007; 28(6): 891-895, indexed in Pubmed: 17530105.

3. Choi SH, Kwon JH, Kim KW, et al. Measurement of liver volumes by portal vein flow by Doppler ultrasound in living donor liver transplantation. Clin Transplant. 2017; 31(9), doi: 10.1111/ctr.13050, indexed in Pubmed: 28681460.

4. Couinaud C. Liver anatomy: portal (and suprahepatic) or biliary segmentation. Dig Surg. 1999; 16(6): 459-467, doi: 10.1159/000018770, indexed in Pubmed: 10805544.

5. Covey AM, Brody LA, Maluccio MA, et al. Variant hepatic arterial anatomy revisited: digital subtraction angiography performed in 600 patients. Radiology. 2002; 224(2): 542-547, doi: 10.1148/radiol.2242011283, indexed in Pubmed: 12147854.

6. Cura M, Haskal Z, Lopera J. Diagnostic and interventional radiology for Budd-Chiari syndrome. Radiographics. 2009; 29(3): 669-681, doi: 10.1148/rg.293085056, indexed in Pubmed: 19448109.

7. Hikspoors JP, Peeters MM, Kruepunga N, et al. Human liver segments: role of cryptic liver lobes and vascular physiology in the development of liver veins and left-right asymmetry. Sci Rep. 2017; 7(1): 17109, doi: 10.1038/ s41598-017-16840-1, indexed in Pubmed: 29214994.

8. Hiroshige S, Shimada M, Harada N, et al. Accurate preoperative estimation of liver-graft volumetry using three-dimensional computed tomography. Transplantation. 2003; 75(9): 1561-1564, doi: 10.1097/01. TP.0000053755.08825.12, indexed in Pubmed: 12792515.

9. Hwang S, Lee SG, Choi ST, et al. Hepatic vein anatomy of the medial segment for living donor liver transplantation using extended right lobe graft. Liver Transpl. 2005; 11(4): 449-455, doi: 10.1002/lt.20387, indexed in Pubmed: 15776411.

10. Iqbal S, Iqbal R, Iqbal F. Surgical implications of portal vein variations and liver segmentations: a recent update. J Clin Diagn Res. 2017; 11(2): AE01-AE05, doi: 10.7860/ JCDR/2017/25028.9453, indexed in Pubmed: 28384848.

11. Jha RC, Khera SS, Kalaria AD. Portal vein thrombosis: imaging the spectrum of disease with an emphasis on MRI features. Am J Roentgenol. 2018; 211(1): 14-24, doi: 10.2214/AJR.18.19548, indexed in Pubmed: 29792748.

12. Kayashima H, Shirabe K, Morita K, et al. Liver regeneration and venous collateral formation in the right lobe living-donor remnant: segmental volumetric analysis and three-dimensional visualization. Transplantation. 2013; 95(2): 353-360, doi: 10.1097/TP.0b013e31827147d8, indexed in Pubmed: 23325006.
13. Kokudo T, Hasegawa K, Uldry E, et al. A new formula for calculating standard liver volume for living donor liver transplantation without using body weight. J Hepatol. 2015; 63(4): 848-854, doi: 10.1016/j.jhep.2015.05.026, indexed in Pubmed: 26057995.

14. Lee WC, Lee CS, Soong RS, et al. Split liver transplantation in adults: preoperative estimation of the weight of right and left hemiliver grafts. Liver Transpl. 2011; 17(1): 93-94, doi: 10.1002/lt.22213, indexed in Pubmed: 21254350.

15. Mohapatra N, Gurumoorthy Subramanya Bharathy K, Kumar Sinha P, et al. Three-dimensional volumetric assessment of graft volume in living donor liver transplantation: does it minimise errors of estimation? J Clin Exp Hepatol. 2020; 10(1): 1-8, doi: 10.1016/j.jceh.2019.03.006, indexed in Pubmed: 32025161.

16. Nakamura T, Tanaka K, Kiuchi T, et al. Anatomical variations and surgical strategies in right lobe living donor liver transplantation: lessons from 120 cases. Transplantation. 2002; 73(12): 1896-1903, doi: 10.1097/00007890-20020627000008, indexed in Pubmed: 12131684.

17. Singh $H$, Rabi S. Study of morphological variations of liver in human. Trans Res Anat. 2019; 14: 1-5, doi: 10.1016/j. tria.2018.11.004.

18. Tongyoo A, Pomfret EA, Pomposelli JJ. Accurate estimation of living donor right hemi-liver volume from portal vein diameter measurement and standard liver volume calculation. Am J Transplant. 2012; 12(5): 1229-1239, doi: 10.1111/j.1600-6143.2011.03909.x, indexed in Pubmed: 22221803.

19. Tsang LLC, Chen CL, Huang TL, et al. Preoperative imaging evaluation of potential living liver donors: reasons for exclusion from donation in adult living donor liver transplantation. Transplant Proc. 2008; 40(8): 2460-2462, doi: 10.1016/j.transproceed.2008.07.075, indexed in Pubmed: 18929768.

20. Tung YC, Cheng YF, Huang TL, et al. Impact of different dominant hepatic vein patterns in left-lobe donors of adult living donor liver transplantation. Transplant Proc. 2016; 48(4): 1012-1014, doi: 10.1016/j.transproceed.2015.12.128, indexed in Pubmed: 27320544.

21. Vaidya S, Dighe $M$, Bhargava $P$, et al. Chronic hepatic artery occlusion with collateral formation: imaging findings and outcomes. Transplant Proc. 2011; 43(5): 1770-1776, doi: 10.1016/j.transproceed.2011.03.034, indexed in Pubmed: 21693276.

22. Zhijun Z, Wei G, Lin W, et al. Middle hepatic vein allocation in adult right lobe living donor liver transplantation. Clin Transplant. 2014; 28(10): 1194-1201, doi: 10.1111/ ctr.12362, indexed in Pubmed: 25328058. 